\title{
PELATIHAN MANAJEMEN ASET DESA DI DESA MEREMPAN HULU KECAMATAN SIAK, KABUPATEN SIAK
}

\author{
Taufeni Taufik*, Yunieta Anisma, Yusralaini, Susilatri \\ Fakultas Ekonomi dan Bisnis, Universitas Riau \\ email: taufentaufik94962@gmail.com
}

\begin{abstract}
Every teaching institution has a tri dharma that must be carried out by its lecturer. One form of tri dharma tertiary education is community service. Community service is carried out so that lecturers use science and technology to advance the welfare of society and educate the nation's life. The form of dedication carried out was village asset management training in Merempan Hulu Village, Siak Subdistrict, Siak District, with 30 participants coming from the villages of Buantan Besar, Langkai, and Merempan Hulu. Participants consisted of the village head, elements of the village apparatus involving KKN students in Merempan Hulu. With the aim of the activity, participants understand the meaning of village asset management, the scope and principles of village asset management. After this training is expected the village head and village apparatus will understand village asset management and village asset management. In this training more than $80 \%$ of participants understood the training on asset management and village asset management.
\end{abstract}

Keywords: Training, Village Asset Management, Merempan Hulu Village, Siak District

\begin{abstract}
Abstrak
Setiap penguruan tinggi memiliki tri dharma yang harus dijalankan oleh dosennya. Salah satu bentuk tri dharma perguruan tinggi adalah pengabdian kepada masyarakat. Pengabdian kepada masyarakat dilakukan agar pada dosen memanfaatkan ilmu pengetahuan dan teknologi untuk memajukan kesejahteraan masyarakat dan mencerdaskan kehidupan bangsa. Adapun bentuk pengabdian yang dilakukan adalah pelatihan manajemen aset desa di Desa Merempan Hulu Kecamatan Siak, Kabupaten Siak, dengan jumlah peserta 30 orang yang berasal dari desa Buantan Besar, Langkai, dan Merempan Hulu. Peserta terdiri dari kepala desa, unsur perangkat desa dengan melibatkan mahasiswa KKN di Merempan Hulu. Dengan tujuan kegiatan, peserta memahami makna manajemen aset desa, lingkup dan prinsip-prinsip pengelolaan aset desa. setelah dilakukan pelatihan ini diharapkan kepala desa dan perangkat desa memahami manajemen aset desa dan pengelolaan aset desa. Dalam pelatihan ini lebih dari $80 \%$ peserta memahami pelatihan manajement aset dan pengelolaan aset desa.
\end{abstract}

Kata kuncis: Pelatihan, Manajemen Aset Desa, Desa Merempan Hulu, Kecamatan Siak

\section{PENDAHULUAN}

Undang-Undang NO 6 tahun 2014 tentang Desa memberi kewenangan, antara lain ; kewenangan berdasarkan hak asal usul dan kewenangan lokal berskala desa yaitu suatu kewenangan untuk mengatur dan mengurus kepentingan masyarakat desa yang telah dijalankan oleh desa atau mampu dan efektif dijalankan oleh desa atau yang muncul karena perkembangan desa dan prakarsa masyarakat desa. Kewenangan lokal skala desa, disamping meningkatkan kapasitas financial desa, melalui, khususnya dana desa (DD) dan alokasi dana desa (ADD), agar desa-desa meningkatkan kemampuannya untuk mengatur dan mengurus kepentingan masyarakat secara efektif guna meningkatkan kesejahteraan masyarakat desa. Namun disadari bahwa kapasitas Desa dalam menyelenggarakan 
pembangunan dalam perspektif "desa membangun" masih terbatas. Keterbatasan itu dapat dideteksi pada arus pelaku (kapasitas aparat pemerintah dan masyarakat), kualitas tata kelola desa, maupun support system yang mewujud melalui regulasi dan kebijakan pemerintah yang terkait dengan Desa. Syarat pencalonan menjadi kepala desa dengan pendidikan minimal tamat sekolah menengah pertama (SMP) (pasal 33 ayat $\mathrm{d}$ UU RI NO. 6 Tahun 2014). Sedangkan persyaratan bagi perangkat desa : bependidikan paling rendah SMU sederajat dengan umur 20-42 tahun ( pasal 2 ayat 2 Permendagri NO. 67 tahun 2017).

Rendahnya regulasi persyaratan pendidikan calon kepala desa dan perangkat desa, mengakibatkan kualitas perencanaan, pelaksanaan, pengendalian dan pemanfaat kegiatan kurang optimal, sehingga kurang memberikan dampak terhadap peningkatkan kesejahteraan masyarakat desa. Untuk itu dalam pengelolaan pembangunan Desa salah satu aspek yang perlu adalah ketersediaan data yang memadai, dan up to date, mengenai kondisi objektif maupun perkembangan desa-desa yang menunjukkan pencapaian pembangunan desa. Ketersediaan data sangat penting bagi semua pihak yang berkepentingan, khususnya bagi pemerintah dalam merumuskan kebijakan pembangunan. Pengelolaan data dimaksud dalam skala nasional, dengan kondisi wilayah khususnya desa-desa di Indonesia yang sangat beragam, tentu memiliki tantangan dan tingkat kesulitan yang besar.

Kepala desa dan Perangkat desa dituntut paham betul soal tata kelola keuangan dan aset desa, mulai dari perencanaan, pelaksanaan, hingga pertanggung jawabannya dengan mengacu pada aturan yang ada. Karena dua komponen tersebut akan menjadi objek pemeriksaan yang akan dilakukan oleh auditor Badan Pemeriksa Keuangan Republik Indonesia (REP-rilis Humas Pemkab Bandung, 2018). Untuk itu menurut Sekda Bandung, perlu adanya pembinaan dalam meningkatkan kinerja para perangkat desa, melalui sosialisasi atau pelatihan kepada kepala desa dan perangkat desa, agar dihasilkan sumber daya manusia (SDM) yang memadai dalam pengelolaan aset dan keuangan desa.

Beberapa penelitian yang dilakukan oleh Resti Wisna Pobela, Herman Karamoy, Linda Lambey, (2017), Muhammad Sahlan (2015), Amrie Firmansyah (2018), menemukan bahwa pengelolaan aset desa masih belum dilaksanakan dengan baik. Beberapa penelitian yang menguji pengaruh kompetensi pengelolaan keuangan desa dilakukan oleh Gamaliel, Hendrik, Sarifudin Madal, Lintje Kalangani (2017), Yudianto, Ivan Ekasarai Sugiarti (2017), Safrizal (2018), menemukan bahwa kompetensi kepala desa dan aparatur desa berpengaruh terhadap pengelolaan keuangan desa. Artinya semakin baik kompetensi kepala desa dan aparatur desa maka pengelolaan keuangan desa dan aset desa semakin baik.

Dari penjelasan analisi situasi diatas, maka perumusan masalah dalam pengabdian masyarakat adalah sebagai berikut : dengan melakukan pelatihan manajamen aset desa diharapkan dapat membantu kepala desa, unsur perangkat desa dalam memahami makna manajemen aset desa, lingkup dan prinsip-prinsip pengelolaan aset desa, .

Tujuan kegiatan pengabdian masyarakat adalah : Peserta memahami makna manajemen aset, ruang lingkup dan prinsip-prinsip pengelolaan aset desa

Manfaat dari kegiatan pengabdian ini adalah ; Supaya kepala desa dan perangkat desa dapat memahami makna manajemen aset desa, ruang lingkup dan prinsipprinsip pengelolaan aset desa dengan baik.

Masyarakat sasaran adalah desa-desa yang ada dikecamatan Siak Kabupaten Siak yang terdiri dari ; kepala desa, unsur perangkat desa yang terdiri dari sekretariat desa, pelaksana kewilayahan dan pelaksana teknis), BPD, lembaga masyarakat desa, kader pemberdayaan masyarakat dan tokoh 
masyarakat yang ada di Kecamatan Siak yang terdiri dari Desa : Desa Buantan Besar, Langkai dan Merempan Hulu.

\section{METODE PENGABDIAN}

Pelatihan pengelolaan aset desa dilakukan dengan cara menggunakan metode sebagai berikut : Metode pelatihan,diskusi, bimbingan dan evaluasi.

Pelatihan dimaknai sebagai upaya proses pemberian pengetahuan dan pemahaman kepada kepala desa, unsur perangkat desa tentang manajemen aset, pengelolaan aset desa berdasarkan peraturan menteri dalam negeri NO. 1Tahun 2016 tentang pengelolaan aset desa.

Diskusi dimaknai sebagai sebuah interaksi komunikasi antara dua orang atau lebih kelompok tentang pelatihan manajemen aset dan pengelolaan aset desa, yang pada akhirnya akan menghasilkan suatu pemahman dari topik tersebut.Bimbingan dimaknai suatu proses pemberian bantuan pengetahuan tentang manajemen aset desa dan pengelolaan aset desa supaya kepala desa dan unsur perangkat desa mampu memecahkan masalah-masalah yang dihadapi.

Evaluasi dimaknai kegiatan yang dilakukan berkenaan dengan proses pelatihan manajemen aset desa dan pengelolaan aset desa untuk menentukan nilai dari suatu kegiatan pelatihan tersebut. merupakan tempat menyebarnya bakteri penyakit Tubercolosis.

\section{HASIL DAN PEMBAHASAN}

Pelaksana kegiatan pengabdian ini dilakukan dengan surat permohonan izin kegiatan yang dikeluarkan oleh ketua jurusan akuntansi FEB Unri Nomor : 034/UN 19.5.1.1.2.3/Ak/2019, tertanggal 16 juli 2019 yang dikeluarkan oleh ketua jurusan akuntansi FEB Unri. Yang diantarkan langsung kepada Penghulu Kampung Merempan Hulu. Setelah izin kegiatan didapat, maka Dekan Fakultas Ekonomi dan Bisnis Universitas Riau menugaskan untuk melaksanakan kegiatan pengabdian pada masyarakat di Desa Merempan Hulu Kabupaten Siak, dengan surat tugas nomor : 6115/UN 19.5.1.1.2/PM.05/2019, tertanggal 1 Agustus 2019.

Kegiatan pengabdian ini dilaksanakan di Desa Merempan Hulu, dengan surat Penghulu Kampung Merempan Hulu Nomor : 145/PEM/KMH/VIII/2019/45 tertanggal 2 Agustus 2019. Dengan diikuti sebanyak 30 orang peserta yang berasal dari Desa Buantan Besar, Langkai, dan Merempan Hulu. Peserta terdiri dari kepala desa, unsur perangkat desa yang terdiri dari sekretaris desa, pelaksana wilayah, pelaksana teknis, BPD, lembaga masyarakat desa, kader pemberdayaan masyarakat, tokoh masyarakat. Kegiatan pengabdian ini melibatkan mahasiswa KKN di Desa Merempan Hulu.

Dalam Pelaksanaan kegiatan pelatihan manajemen aset desa, para peserta diberi pelatihan tentang konsep teori yang meliputi pengertian tentang aset, klasifikasi aset, manajemen aset, pengelolaan aset desa, dan pemegang kekuasaan pengelolaan aset desa tersebut. Optimalisasi pengelolaan aset, asas-asas pengelolaan keuangan desa, cara pengelolaan aset desa, pemanfaatan aset desa, pengamanan aset desa, penghapusan aset desa, pemindah tanganan aset desa, penata usahaan aset desa, penilaian aset desa dan tukar menukar aset desa. Kegiatan pelatihan ini berdasarkan Peraturan Menteri Dalam Negeri (Permendagri) No 1 Tahun 2016 tengan pengelolaan aset desa.

Evaluasi selama proses pelatihan meliputi, keterlibatan dan kemampuan peserta dalam setiap tahap pelatihan. Pada tahap akhir, peserta diharapkan dapat memahami ; makna manajemen aset desa; ruang lingkup manajemen aset desa ; dan prinsip-prinsip pengelolaan aset desa. Dalam pelatihan ini lebih dari $80 \%$ peserta memahami kegiatan pelaksanaan pelatihan manajemen aset desa dan pengelolaan aset desa. Berikut gambar kegiatan pelatihan: 


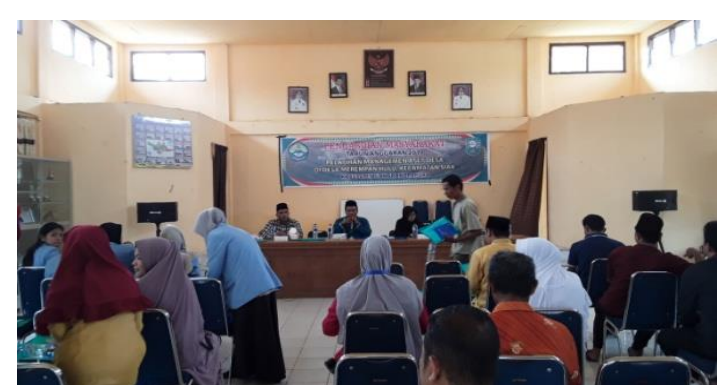

Gambar 1. Pembagian bahan pelatihan untuk para peserta

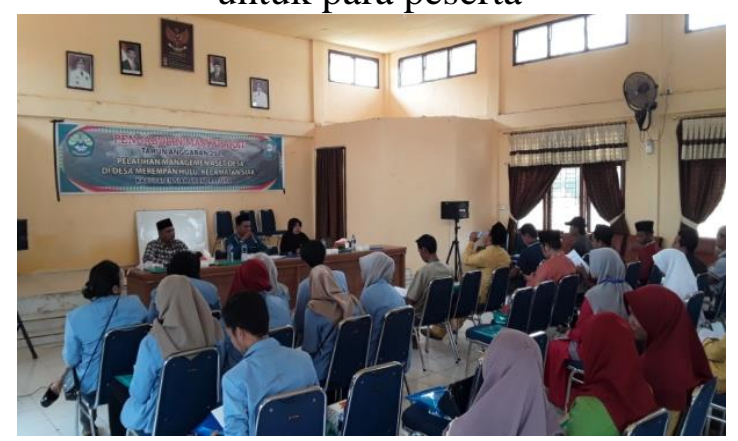

Gambar 2. Foto pembukaan pelatihan oleh

Penghulu Kampung Merempan Hulu.

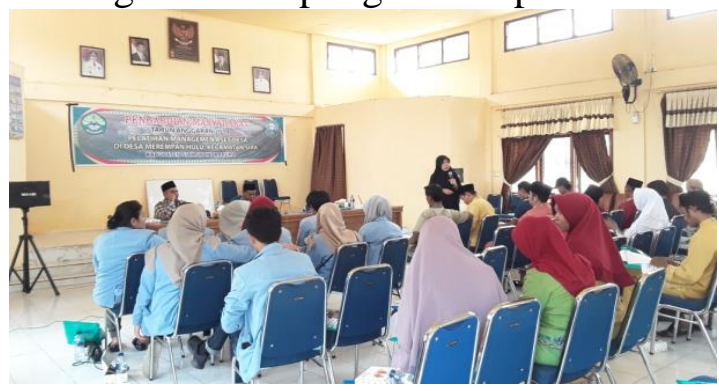

Gambar 3. Penyampaian materi pelatihan

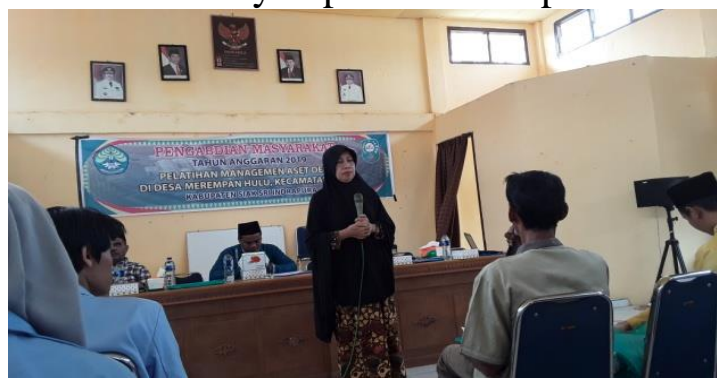

Gambar 4. Penyampaian tanya-jawab oleh peserta pelatihan

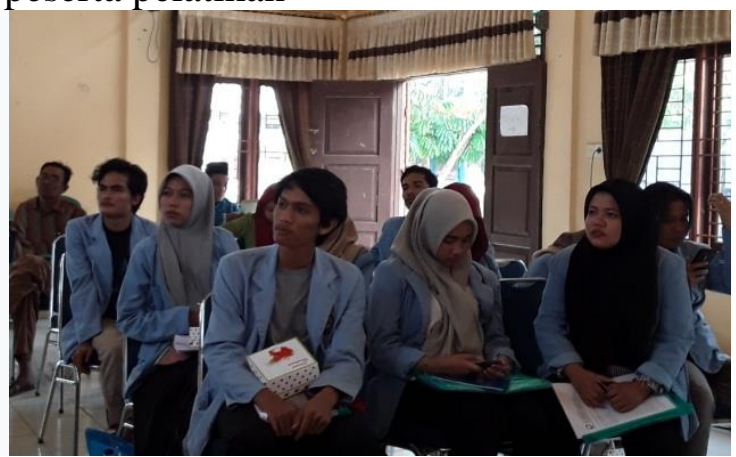

Gambar 5. Perhatian Mahasiswa KKN yang dilibatkan dalam pelatihan

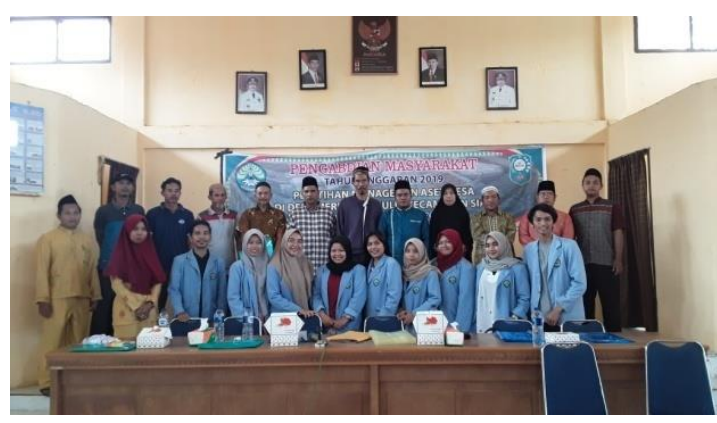

Gambar 6. Foto bersama sebagian peserta, setelah selesai acara pelatihan

\section{SIMPULAN}

Para pemegang kekuasaan pengelolaan aset desa (PKPAD), berwenang dan bertanggung jawas atas pengelolaan aset desa, kepada pihak internal dan eksternal. Kepala desa dan perangkat desa dituntut paham betul soal tata kelola keuangan dan aset desa. Karena komponen tersebut menjadi objek pemerikan Badan PemeriksaKeuangan.

Rendahnya regulasi persyaratan pendidikan calon kepala desa (tamat SMP) dan perangkat desa (tamat SMU), dan berdasarkan hasil penelitian ditemukan bahwa pengelolaan aset desa belum dilakukan secara optimal, maka dipandang perlu untuk mengadakan pelatihan dengan tujuan supaya peserta memahami pengelolaan aset desa dengan baik. Hasil evaluasi kegiatan pelatihan pengelolaan aset desa, peserta memahami lebih dari 80 $\%$. Dengan demikian disimpulkan para peserta memahami pelatihan tersebut.

\section{UCAPAN TERIMA KASIH}

Terima kasih kami ucapkan kepada semua pihak yang mendukung kelancaran pengabdian ini terutama untuk Lembaga Penelitian dan Pengabdian kepada Masyarakat (LPPM) Universitas Riau, Penghulu Kampung Desa Merempan Hulu, Kecamatan Siak Kabupaten Siak serta para peserta pelatihan yang meliputi kepala desa, perangkat desa dan mahasiswa Kuliah Kerja Nyata (KKN) Universitas Riau yang terlibat dalam kegiatan pengabdian masyarakat ini. 


\section{DAFTAR PUSTAKA}

[1] Amrie Firmansyah, 2018, Pengelolaan Aset di Kabupaten Tangerang, Departmen of Accountingm Polytechnic of state finance STAN, JIAKES, jurnal Ilmiah Akuntansi Kesatuan, Vol 6 No., April 2018 pg 001-008 STIE Kesatuan ISSN 2337-7852.

[2] Dadi Haryadi, 2018, Pengelolaan Keuangan dan Aset Desa, Jadi Objek Audit BPK, Ayo bandung.Diponegoro Semarang.

[3] Gamaliel, Hendrik, Sarifudin Mada I, Lintje Kalangi, 2017, Pengaruh Kompetensi Apatar Pengelola Dana Desa, Komitmen Organisasi Pemerintah Desa dan Partisipasi Masyarakat Terhadap Akuntabilitas Pengelolaan Dana Desa di Kabupaten Gorontalo, Program Magister Akuntansi, Fakultas Ekonomi dan Bisnis Universitas Sam Ratulangi

[4] Muhammad Sahlan, 2015, Analisis Permasalahan Aset Tetap pada Laporan Keuangan Pemerintah Daerah, Studi Kasus Pada Entitas Pemerintah Daerah di Provinsi Papua Barat), Skripsi Fakultas Ekonomi dan Bisnis, Universitas

[5] Permendagri NO. 67 Tahun 2017 tentang Perubahan atas Peraturan Menteri Dalam Negeri NO 83 Tahun 2015 tentang Penangkatan dan Perberhentian Perangkat Desa

[6] REP-Rilis Humas Pemkab Bandung, 2018, Pengelolaan Keuangan dan Aset Desa, Jadi Objek Audit BPK, htps://jabarprov.go.id, 31 Oktober, Jawa Barat.

[7] Yusuf, Pengawasan dan Pengendalian Aset Desa, Inspektorat Karanganyar.

[8] Yudianto, Ivan, Ekasari Sugiarti, 2017, Analisis Faktor Kompetensi sumber Daya Manusia, Pemanfaatan Teknologi informasi, dan Partisipasi Penganggaran terhadap Akuntabilitas Pengelolaan Dana Desa (Survei pada Desa-Desa di Wilayah kecamatan Klari, Kecamatan Karawang Timur, Kecamatan Majalaya dan Kecamatan Rengasdengklok Kabupatan Karaawang), ISSN 2252-3936.

[9] Yusuf, Pengawasan dan Pengendalian Aset Desa, Inspektorat Karanganyar, inspektorat karanganyar go.id

[10] Resti Wisna Pobela, Hemran Karamoy, Linda Lambey, 2017, Analisis Pengelaloaan Aset Desa di Kota Kotamobagu, Jurnal Riset Akuntansi dan Auditing, Volume 8 NO. 2.

[11] Safrizal, 2018, Pengaruh Otonomi Desa, Partisipasi Masyarakat, Kompetensi, Komitmen Aparatur Desa, Transparansi dan Akuntabilitas Terhadap Pengelolaan Keuangan Dana Desa, di Kecamatan Kempas Kabupaten Indragiri Hilir, skripsi Fakultas Ekonomi dan Bisnis Universitas Riau.

[12] Undang-Undang RI NO. 6Tahun 2014 tentang Desa, Penerbit Sinar Grafika, 2017. 